\title{
Intragenic deletions of the IGF1 receptor gene in five individuals with psychiatric phenotypes and developmental delay
}

\author{
Jens Witsch ${ }^{1}$, Przemyslaw Szafranski ${ }^{2}$, Chun-An Chen ${ }^{2}$, LaDonna Immken ${ }^{3}$, Gayle Simpson Patel ${ }^{3}$, \\ Patricia Hixson ${ }^{2}$, Sau Wai Cheung ${ }^{2}$, Pawel Stankiewicz ${ }^{2}$ and Christian P Schaaf ${ }^{\star}$
}

Haploinsufficiency of the gene encoding the insulin-like growth factor 1 receptor (IGF1R), either caused by telomeric 15q26 deletions, or by heterozygous point mutations in IGF1R, segregate with short stature and various other phenotypes, including microcephaly and dysmorphic facial features. Psychomotor retardation and behavioral anomalies have been seen in some cases. Here we report small, intragenic deletions of IGF1R, identified by chromosome microarray analysis in two unrelated families affected primarily with neuropsychiatric phenotypes including developmental delay, intellectual disability and aggressive/ autoaggressive behaviors. The deletions are in frame, and both wild-type and mutant mRNAs are expressed as measured by quantitative real-time PCR. While short stature is considered a phenotypic hallmark of IGF1R haploinsufficiency, the present report suggests that in frame exon deletions of IGF1R present predominantly with cognitive and neuropsychiatric phenotypes. European Journal of Human Genetics (2013) 21, 1304-1307; doi:10.1038/ejhg.2013.42; published online 13 March 2013

Keywords: 15q26.3; IGF1 receptor; microdeletion; neuropsychiatric disease

\section{INTRODUCTION}

The gene encoding the insulin-like growth factor 1 receptor (IGF1R), located on the long arm of chromosome 15, is involved in somatic development and glucose metabolism. Numerous telomeric deletion cases of $15 \mathrm{q}$, resulting in the loss of IGF1R as well as rare cases of heterozygous missense and nonsense mutations of IGF1R have been reported. They were associated with various constellations of clinical findings, including growth deficit, microcephaly, developmental delay, mild facial dysmorphisms and skeletal deformations in affected individuals. ${ }^{1-11}$

Usually intrauterine or postnatal growth deficits were moderate to severe in these patients. Notably, cognitive dysfunction of the reported individuals was either moderate, mild or absent. ${ }^{2-4}$ Significant psychiatric comorbidites beyond cognitive impairment have not been reported to date.

Although most cases represent large telomeric deletions, involving many genes, a recent report presented a three-generation Dutch family with a small $(0.095 \mathrm{Mb})$ deletion, affecting only exons 11-21 of $I G F 1 R$ and one nearby gene. Seven family members carried the deletion, and all were affected with short stature $(-2.5$ to -4.4 $\mathrm{SD}$ below the mean). All affected individuals showed average to above-average scores on IQ testing. Clinical neurodevelopmental deficits, namely mild speech and motor delay during early childhood, were detected in the index patient only. ${ }^{10}$

Here, we report five individuals with intragenic exon deletions of $I G F 1 R$ in two unrelated families, segregating predominantly with cognitive and neuropsychiatric phenotypes. None of the five individuals had short stature, defined as equal or greater than $2 \mathrm{SD}$ below the mean for age and gender. In both families, the microdeletions were inherited maternally.

\section{MATERIALS AND METHODS}

\section{Human subjects}

Both probands were referred to the Medical Genetics Laboratories, Baylor College of Medicine (BCM), Houston, TX, USA, for clinical array comparative genomic hybridization (aCGH) analysis. The study was approved by the Institutional Review Board of BCM, and all participants were recruited after informed consent was obtained.

\section{Array comparative genomic hybridization}

Patient DNA was analyzed using the Baylor College of Medicine clinical genomic microarray (version 8.2 in individual I-1, version 8.1 in individual II1), described in Boone et al. ${ }^{12}$ Given the small deletion size, microarray findings were confirmed by polymerase chain reaction (Supplementary Figure S1) in individual I-1.

All genomic coordinates refer to the February 2009 assembly of the reference genome (GRCh37/hg19). Exon numbering is based on RefSeq transcript NM_000875.3.

\section{Quantitative real-time PCR}

RNA was extracted from fresh, whole blood using the PAXgene Blood RNA Kit (PreAnalytiX, Hombrechtikon, Switzerland). RNA was treated with DNase using DNA-free kit (Ambion, Grand Island, NY, USA), and reverse-transcribed using High Capacity cDNA Reverse Transcription Kit (Applied Biosystems, Grand Island, NY, USA). Real-time PCR amplification of IGF1R wild-type copy (exons 2-3 boundary) was done using Power SYBR Green Kit (Applied Biosystems) and primers IGF1R_F2 (5'-CGATGTGTGAGAAGACCACC-3',

${ }^{1}$ Department of Neurology, Charité University Medicine, Campus Virchow Klinikum, Berlin, Germany; ${ }^{2}$ Department of Molecular and Human Genetics, Baylor College of Medicine, Houston, TX, USA; ${ }^{3}$ Specially for Children, Austin, TX, USA

${ }^{*}$ Correspondence: Professor CP Schaaf, Department of Molecular and Human Genetics, Baylor College of Medicine, Jan and Dan Duncan Neurological Research Institute, 1250 Moursund Street, Suite 1325, Houston, TX 77030, USA. Tel: + 1832824 8787; Fax: + 1832825 1251; E-mail: schaaf@bcm.edu

Received 17 August 2012; revised 29 January 2013; accepted 13 February 2013; published online 13 March 2013 
mapping within exon 2) and IGF1R_R (5'-TGGCAGCACTCATTGTTCTC-3', mapping within exon 3 deleted in all patients; qPrimerDepot at http:// primerdepot.nci.nih.gov/). Primers to amplify internal control GAPDH gene were GAPDH_F1 (5'-AAGGTGAAGGTCGGAGTCAA- $\left.3^{\prime}\right)$ and GAPDH_R1 (5'-AATGAAGGGGTCATTGATGG-3'; qPrimerDepot). Quantification of combined expression of mutant and wt alleles was done using TagMan assays specific for IGF1R exons 10-11 boundary and GAPDH as a control (Applied Biosystems). The relative expression of mutant allele of IGF1R was deduced by subtracting wild-type allele expression from combined mutant and wild-type allele expression. qPCR conditions included 40 cycles of $95^{\circ} \mathrm{C}$ for $15 \mathrm{~s}$ and $60{ }^{\circ} \mathrm{C}$ for $1 \mathrm{~min}$. All experiments were done in triplicate.

\section{RESULTS}

\section{Clinical cases}

From June 2009 through November 2011, 15632 individuals were referred to the Medical Genetics Laboratory of Baylor College of Medicine for clinical chromosome microarray testing. Among these, 10 probands were found to have heterozygous deletions encompassing sequence of the IGF1R gene ( $0.064 \%$ of all cases). In 7 of the 10 cases, the entire IGF1R gene was deleted, similar to previously described cases of IGF1R haploinsufficiency. ${ }^{6-9,11}$ One case deleted only the last exon of IFG1R and three exons of a neighboring gene, PGPEP1L. Two cases appeared particularly interesting, as they harbored intragenic deletions of one and three IGF1R exons, respectively. These two were subsequently studied in more detail, and clinical phenotypic information was obtained.

Case 1. Individual I-1, a 7-year-old boy of Indian-European descent, presented to the pediatric genetics clinic for evaluation of global developmental delay and abnormal behaviors. Psychiatric symptoms included hyperactivity, extreme temper and mood, aggressive and autoaggressive behavior. He had had two previous hospitalizations to psychiatric inpatient units for violent behaviors. At the time of his visit, he was on risperidone, guanfacine and dextroamphetamine/ amphetamine. He had previously been evaluated by a developmental pediatrician, and developmental quotients were between 40 (for problem-solving) and 50 (for language and gross motor skills).
Body height was in the lower normal range on the 10th percentile. The remainder of the physical examination revealed borderline microcephaly (on the second percentile for age and gender) and subtle dysmorphic facial features, including mild synophrys, mild epicanthal folds and widely spaced teeth.

His mother, individual I-2, was a 31-year-old female with a history of bipolar and anxiety disorder, diagnosed at the age of 11 years, with one suicide attempt at age 26 years. She graduated from high school and never required special education. Information on early development was not available for this individual.

Case 2. Patient II-1, a 21-month-old boy, presented to the clinical geneticist for evaluation of abnormal behavior, speech delay, microcephaly and poor weight gain, as well as a family history of learning and growth problems. Body height was in the lower normal range (on the ninth percentile; Table 1).

The proband's brother (II-2) had global developmental delay, autoaggressive and aggressive/oppositional behavior toward others. Their mother (II-3) had a history of autoaggressive behaviors as a child, and cognitive delays. Body stature was low in the brother (3rd percentile), but within the normal range in the mother (30th percentile). No dysmorphic facial features or skeletal anomalies were present in individuals II-1, II-2 and II-3. At the time of referral to the clinical geneticist, none of the family members had been seen by a psychiatrist.

\section{Molecular analysis}

In proband I-1, aCGH revealed a heterozygous deletion of $2 \mathrm{~kb}$ (minimum interval) to $16 \mathrm{~kb}$ (maximum interval) in size (Figures 1a and c), deleting the entire exon 3 of IGF1R on chromosome $15 \mathrm{q} 26.3$ (Figure 1c). The same microdeletion was found in the proband's mother (I-2). In individual I-1, laboratory testing revealed IGF-1 and IGF-binding protein (IGF-BP) levels in serum within the normal range (IGF-1: $100 \mathrm{ng} / \mathrm{ml}$; IGF-BP: $4.3 \mathrm{mg} / \mathrm{l}$ ).

In proband II-1, aCGH revealed a heterozygous intragenic loss of $40 \mathrm{~kb}$ (minimum interval) to $58 \mathrm{~kb}$ (maximum interval) in size,

Table 1 Clinical and molecular characteristics of five individuals with IGF1R exon deletions

\begin{tabular}{|c|c|c|c|c|c|}
\hline & I-1 (Proband) & I-2 (Mother) & II-1 (Proband) & II-2 (Brother) & II-3 (Mother) \\
\hline Age at diagnosis & 7 years & 31 years & 21 months & 4 years & 26 years \\
\hline Sex & Male & Female & Male & Male & Female \\
\hline Ethnicity & Indian-European & Indian-European & European & European & European \\
\hline Cognitive function & Moderate ID & Normal & $\begin{array}{l}\text { Global developmental } \\
\text { delay }\end{array}$ & $\begin{array}{l}\text { Global developmental } \\
\text { delay }\end{array}$ & $\begin{array}{l}\text { Impaired. No formal } \\
\text { testing. }\end{array}$ \\
\hline \multirow[t]{2}{*}{ Body height } & 10th percentile $(118.2 \mathrm{~cm})$ & 5th percentile $(152.5 \mathrm{~cm})$ & 9th percentile $(82.5 \mathrm{~cm})$ & 3rd percentile $(95 \mathrm{~cm})$ & 30th percentile $(160 \mathrm{~cm})$ \\
\hline & Z-score: -1.3 & Z-score: -1.7 & Z-score: -1.3 & Z-score: -1.9 & Z-score: -0.5 \\
\hline $\begin{array}{l}\text { Psychiatric } \\
\text { phenotype }\end{array}$ & $\begin{array}{l}\text { Hyperactivity, aggressive and } \\
\text { autoaggressive behavior }\end{array}$ & $\begin{array}{l}\text { Bipolar and anxiety } \\
\text { disorders }\end{array}$ & Autoaggressive behavior & $\begin{array}{l}\text { Aggressive and autoag- } \\
\text { gressive behavior }\end{array}$ & $\begin{array}{l}\text { Autoaggressive behavior } \\
\text { during childhood }\end{array}$ \\
\hline Molecular phenotype & IGFIR microdeletion, exon 3, $2 \mathrm{~kb}$ & $\begin{array}{l}\text { IGF1R microdeletion, } \\
\text { exon } 3,2 \mathrm{~kb}\end{array}$ & $\begin{array}{l}\text { IGF1R microdeletion, } \\
\text { exons } 3-5,40 \mathrm{~kb}\end{array}$ & $\begin{array}{l}\text { IGF1R microdeletion, } \\
\text { exons } 3-5,40 \mathrm{~kb}\end{array}$ & $\begin{array}{l}\text { IGF1R microdeletion, } \\
\text { exons } 3-5,40 \mathrm{~kb}\end{array}$ \\
\hline Minimal interval & Chr15:99434 081-99435876 & $\begin{array}{l}\text { Chr15:99434 081- } \\
99435876\end{array}$ & $\begin{array}{l}\text { Chr15:99403439- } \\
99443615\end{array}$ & $\begin{array}{l}\text { Chr15:99403 439- } \\
99443615\end{array}$ & $\begin{array}{l}\text { Chr15:99403439- } \\
99443615\end{array}$ \\
\hline Maximal interval & Chr15:99424 326-99439855 & $\begin{array}{l}\text { Chr15:99424326- } \\
99439855\end{array}$ & $\begin{array}{l}\text { Chr15:99393 779- } \\
99451587\end{array}$ & $\begin{array}{l}\text { Chr15:99393 779- } \\
99451587\end{array}$ & $\begin{array}{l}\text { Chr15:99393 779- } \\
99451587\end{array}$ \\
\hline Inheritance & Mat & Unknown & Mat & Mat & Unknown \\
\hline IGF1 level & Normal & Unknown & Normal & Unknown & Unknown \\
\hline IGF-BP & Normal & Unknown & Normal & Unknown & Unknown \\
\hline Other chromosomal & None & None & None & None & Dup 21q22.3. (18kb) \\
\hline
\end{tabular}

abnormalities

Abbreviations: ID, intellectual disability; IGF1, insulin-like growth factor 1; IGF-BP, insulin-like growth factor-binding protein; Mat, maternal. 

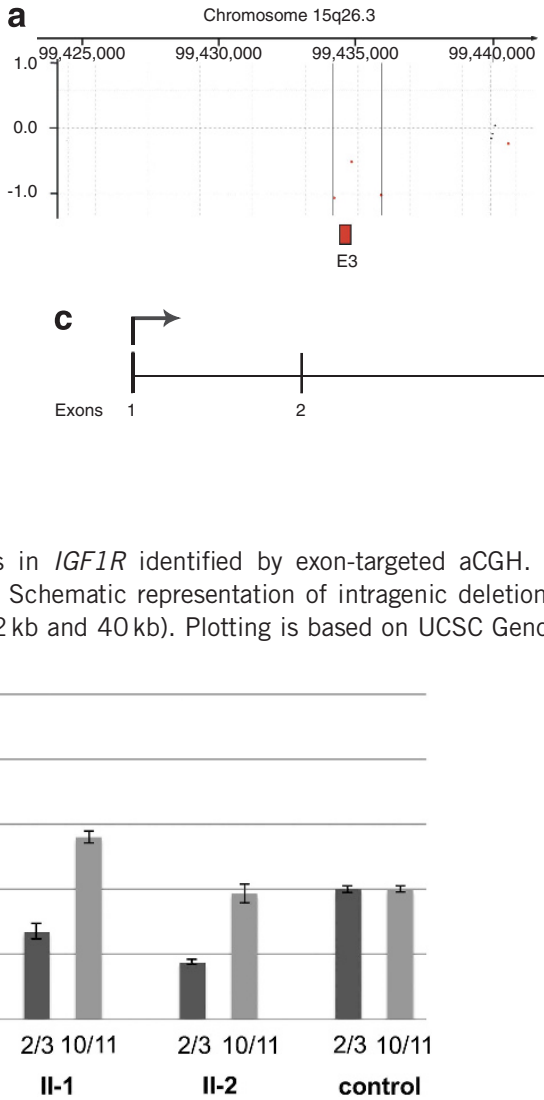

Figure 2 Quantitative real-time PCR analysis of IGFIR mRNA in peripheral blood. ' $2 / 3$ ' Indicates the abundance of wild-type IGFIR mRNA, amplified by using primers flanking the exon 2/exon 3 boundary. '10/11' Indicates the abundance of total (wild-type and mutant) IGF1R mRNA, using primers flanking the exon 10/exon 11 boundary. The abundance of mutant IGFIR mRNA can be deduced by subtracting the wild-type (2/3) expression from the total $(10 / 11)$ expression. Note the inter- and intra-familial variability of IGF1R mRNA expression. All expression levels are normalized to GAPDH and to a normal, age-matched control. All reactions were carried out in triplicate; error bars indicate SD.

equivalent to exons 3-5 of IGF1R (Figures $1 \mathrm{~b}$ and $\mathrm{c}$ ). The same microdeletion was found to be present in the proband's mother (II-3) and in one brother (II-2). The mother also carried a microduplication in 21q22.3 (minimal interval: chr22:47 848 308-47 866257 ) containing one RefSeq gene, PCNT, biallelic loss-of-function mutations of which cause microcephalic osteodysplastic primordial dwarfism type II and Seckel syndrome. Duplications of PCNT have not been associated with human disease.

No other aCGH abnormalities were found in II-1 or II-2. In II-1 IGF-1 and IGF-BP plasma levels were within normal range (121 ng/ml; IGF-BP: $3.2 \mathrm{mg} / \mathrm{l}$ ).

Quantitative real-time PCR analysis was conducted to determine the expression and stability of both wild-type and mutant alleles of IGF1R (Figure 2). While primers and probes flanking the exons 10-11 boundary of $I G F 1 R$ were used to determine the total abundance of (wild-type and mutant) IGF1R mRNA, those flanking the exons 2-3 boundary detect wild-type IGF1R only, given that exon 3 is deleted in all patients included in this report. Expression levels were normalized to GAPDH and to a normal, age-matched control. The abundance of mutant IGF1R mRNA can be deduced by subtracting wild-type allele expression (exons 2-3 product) from total expression (exons 10-11 product). In all individuals tested, total expression (as determined by

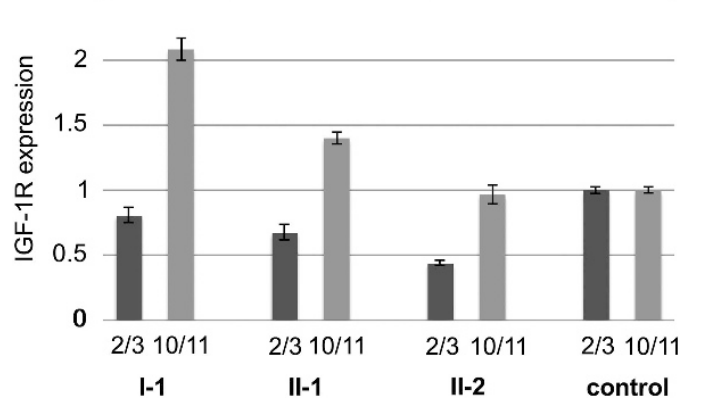

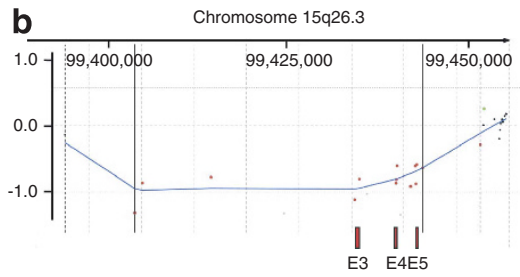

IGF1R
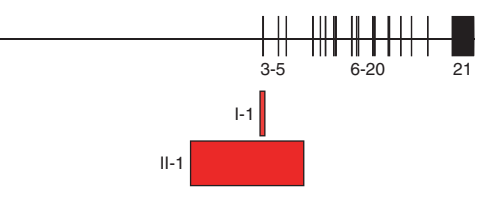

Figure 1 Intragenic deletions in IGFIR identified by exon-targeted aCGH. (a, b) Microarray plots of index patient I-1 (a) and II-1 (b). Deleted exons 作

the exons 10-11 product) was higher than wild-type expression (as determined by the exons $2-3$ product), suggesting that both the wildtype and mutant alleles are stably expressed on an mRNA level, at least in peripheral blood. The ratio of mutant allele expression to wild-type allele expression was 1:1.58 (individual I-1), 1:1.07 (individual II-1) and 1:1.21 (individual II-2), respectively.

\section{DISCUSSION}

The IGF-1 receptor contributes to somatic growth and brain development by mediating cell proliferation, survival and differentiation. ${ }^{13}$ The IGF1 receptor consists of two extracellular alpha-subunits that provide a binding site for IGFs and two transmembrane beta-subunits associated with a tyrosine-kinase-dependent second messenger system. In the central nervous system, the subsequent signaling cascade mediates a neuroprotective effect by inhibiting apoptosis. $^{14-16}$

Previously reported cases of terminal $15 q$ deletions entailing IGF1R haploinsufficiency had heterogenous phenotypes, including intrauterine and postnatal growth delay, microcephaly, dysmorphic facial features, skeletal anomalies and speech and motor delay. Missense and nonsense mutations in IGF1R segregated with short stature, mild dysmorphic facial features, mostly mild developmental delay and mild psychiatric features in one reported case. ${ }^{1-5}$

Although the variable phenotype of previously reported patients with $15 q 26.3$ deletions may be attributable, at least in part, to genes other than IGF1R, it is notable that the smallest IGF1R deletion reported to date segregated predominantly with short stature and no or mild neuropsychiatric disorders. ${ }^{10}$ In that family described by Veenma et al, seven family members carried a deletion of exons 11-21 of the IGF1R gene and what at the time of publication used to be a hypothetical protein-locus (LOC145814), and is now annotated as a RefSeq gene, PGPEP1L, encoding pyroglutamyl-peptidase-I-like. Body heights in the seven probands were 4.04, 2.72, 4.42, 3.01, 2.5, 4.0 and 3.09 (mean: 3.4) SD below the age-specific reference groups. ${ }^{17}$ Mild motor and speech delay and behavioral abnormalities were present in only one of the seven cases.

Our findings suggest a wider phenotypic spectrum of $I G F 1 R$ mutations, including significant neuropsychiatric ailments. We describe two small intragenic IGF1R deletions, including exon 3 and exons 3-5, with maternal inheritance in two unrelated families. These cases of intragenic exon deletions of IGF1R appear to be rare ( 2 in 15632 in our cohort of samples submitted for clinical, exon-targeted oligonucleotide chromosome microarray analysis). 
No validated intragenic exon deletions of IGF1R were listed in the database of genomic structural variation (dbVar), neither in the Database of Chromosomal Imbalance and Phenotype in Humans using Ensembl Resources at the time of submission of the manuscript.

Phenotypes in our five patients included global developmental delay or intelligence deficit (4/5), and autoaggressive (4/5) and aggressive (2/5) behaviors during childhood. In addition, in one of our cases bipolar and anxiety disorders with one suicide attempt were reported. Our cases exhibited a mean body height of -1.34 SD below the mean for age and gender, using the 2000 CDC growth charts for the United States as a reference, consistent with borderline low or even normal stature (Table 1).

The phenotypic spectrum of our cases extends beyond the phenotypes resulting from IGF1R point mutations described previously. These were located in exons 2, 7, 11 and 16, respectively. ${ }^{1-5}$ Short stature was present in all cases, mild motor and/or speech developmental delay in 4/9 cases and mild intellectual disability with a Wechsler intelligence quotient of 60 - in one case of a patient with a missense mutation in exon 11 . This missense mutation was detected in a girl whose mother, a carrier of the same mutation, did not show any neuropsychiatric abnormalities and had normal intelligence. $^{2}$ Mild psychiatric anomalies, namely anxious affect, obsessive tendencies, psychomotor agitation, were present in one case. ${ }^{1}$ Other neuropsychiatric symptoms, specifically aggressive or autoaggressive behaviors, were not described in these patients.

Interestingly, both cases reported herein delete segments in frame, as exon 3 has $312 \mathrm{bp}$, and exons 3-5 a total of $606 \mathrm{bp}$, both of which are multiples of three. Quantitative real-time PCR studies show that mRNA from both wild-type and mutant alleles is detectable in peripheral blood, suggesting stability of both products. It is conceivable that both might still be translated into functional proteins. Unfortunately, IGF1R protein is not expressed at sufficient levels in lymphocytes to be detectable by western blot analysis (data not shown). However, given the patients' phenotypes, with absence of significant short stature or skeletal anomalies, one could speculate that the resulting, mutated proteins work reasonably well, stimulating somatic growth, but still cause cognitive and psychiatric phenotypes, based on IGF1R's role in the central nervous system.

Postnatal impact of IGF1 knockout in mice is strongest in brain regions that exhibit a high degree of plasticity into adult life, for example, hippocampal granule cells, reflecting a long-lasting IGF-dependency of cells in these brain areas. ${ }^{18,19}$ Although IGF1 interactions with its receptor are complex and influenced by IGF-1-binding proteins, postnatal IGF1R dysfunction would also be expected to functionally impact these brain areas. During embryonic development, however, IGF1 mRNA is transiently expressed in many brain regions, including areas containing long projection neurons. ${ }^{18,20,21}$

Although IGF1R dysfunction in hippocampal neurons might be associated with the predominance of learning and memory deficits seen in many patients with IGF1R mutations, one could hypothesize that disturbances of cortical long-projection neurons might account for some of the neuropsychiatric symptoms seen in our patients. ${ }^{18}$

However, it remains elusive how such differential impact on distinct neuronal subgroups might be caused by different deletions and mutations affecting the IGF1R gene.

Discovery of further clinical cases is warranted in order to establish clear phenotype-genotype causality of heterozygous IGF1R dysfunction.

\section{CONFLICT OF INTEREST}

Drs Schaaf, Stankiewicz and Cheung are faculty members of the Department of Molecular and Human Genetics at Baylor College of Medicine, which derives revenue from the chromosomal microarray analysis offered in the Medical Genetics Laboratory. The remaining authors declare no conflict of interest.

\section{ACKNOWLEDGEMENTS}

We thank the patients and parents for their willingness to participate in our research study. Dr Schaaf 's work is generously supported by the Joan and Stanford Alexander family, the Doris Duke Charitable Foundation, and the Ting Tsung and Wei Fong Chao Foundation. Dr Witsch's work was supported by the Felgenhauer Foundation of the German Neurological Society. We thank Mrs Jessica Tao for excellent technical assistance.

1 Abuzzahab MJ, Schneider A, Goddard A et al: IGF-I receptor mutations resulting in intrauterine and postnatal growth retardation. N Engl J Med 2003; 349: 2211-2222.

2 Kawashima Y, Kanzaki S, Yang F et al: Mutation at cleavage site of insulin-like growth factor receptor in a short-stature child born with intrauterine growth retardation. J Clin Endocrinol Metab 2005; 90: 4679-4687.

3 Raile K, Klammt J, Schneider A et al: Clinical and functional characteristics of the human Arg59Ter insulin-like growth factor i receptor (IGF1R) mutation: implications for a gene dosage effect of the human IGF1R. J Clin Endocrinol Metab 2006; 91: 2264-2271.

4 Inagaki K, Tiulpakov A, Rubtsov P et al: A familial insulin-like growth factor-I receptor mutant leads to short stature: clinical and biochemical characterization. J Clin Endocrinol Metab 2007; 92: 1542-1548.

5 Walenkamp MJ, Karperien M, Pereira AM et al: Homozygous and heterozygous expression of a novel insulin-like growth factor-I mutation. J Clin Endocrinol Metab 2005; 90: 2855-2864.

6 Ester WA, van Duyvenvoorde HA, de Wit CC et al: Two short children born small for gestational age with insulin-like growth factor 1 receptor haploinsufficiency illustrate the heterogeneity of its phenotype. J Clin Endocrinol Metab 2009; 94: 4717-4727.

7 Pinson L, Perrin A, Plouzennec $\mathrm{C}$ et al: Detection of an unexpected subtelomeric $15 q 26.2->$ qter deletion in a little girl: clinical and cytogenetic studies. Am J Med Genet A 2005; 138A: 160-165.

8 Rujirabanjerd S, Suwannarat W, Sripo T, Dissaneevate P, Permsirivanich W, Limprasert $P$ : De novo subtelomeric deletion of $15 q$ associated with satellite translocation in a child with developmental delay and severe growth retardation. Am J Med Genet A 2007; 143: 271-276.

9 Walenkamp MJ, de Muinck Keizer-Schrama SM, de Mos M et al: Successful long-term growth hormone therapy in a girl with haploinsufficiency of the insulin-like growth factor-I receptor due to a terminal 15 q26.2-> qter deletion detected by multiplex ligation probe amplification. J Clin Endocrinol Metab 2008; 93: 2421-2425.

10 Veenma DC, Eussen HJ, Govaerts LC et al: Phenotype-genotype correlation in a familial IGF1R microdeletion case. J Med Genet 2010; 47: 492-498.

11 Rudaks LI, Nicholl JK, Bratkovic D, Barnett CP: Short stature due to $15 q 26$ microdeletion involving IGF1R: report of an additional case and review of the literature. Am J Med Genet A 2011; 155: 3139-3143.

12 Boone PM, Bacino CA, Shaw CA et al: Detection of clinically relevant exonic copynumber changes by array CGH. Hum Mutat 2010; 31: 1326-1342.

13 Joseph D'Ercole A, Ye P: Expanding the mind: insulin-like growth factor I and brain development. Endocrinology 2008; 149: 5958-5962.

14 Delcourt N, Thouvenot E, Chanrion B et al: PACAP type I receptor transactivation is essential for IGF-1 receptor signalling and antiapoptotic activity in neurons. EMBO J 2007; 26: 1542-1551.

$15 \mathrm{Tu} \mathrm{H}, \mathrm{Xu} \mathrm{C}$, Zhang W et al: GABAB receptor activation protects neurons from apoptosis via IGF-1 receptor transactivation. J Neurosci 2010; 30: 749-759.

16 D'Mello SR, Galli C, Ciotti T, Calissano P: Induction of apoptosis in cerebellar granule neurons by low potassium: inhibition of death by insulin-like growth factor I and CAMP. Proc Natl Acad Sci USA 1993; 90: 10989-10993.

17 Fredriks AM, van Buuren S, Burgmeijer RJ et al: Continuing positive secular growth change in the Netherlands 1955-1997. Pediatr Res 2000; 47: 316-323.

18 Bondy CA: Transient IGF-I gene expression during the maturation of functionally related central projection neurons. J Neurosci 1991; 11: 3442-3455.

19 Beck KD, Powell-Braxton L, Widmer HR, Valverde J, Hefti F: Igf1 gene disruption results in reduced brain size, CNS hypomyelination, and loss of hippocampal granule and striatal parvalbumin-containing neurons. Neuron 1995; 14: 717-730.

20 Bondy CA, Lee WH: Patterns of insulin-like growth factor and IGF receptor gene expression in the brain. Functional implications. Ann N Y Acad Sci 1993; 692: 33-43.

21 Rotwein P, Burgess SK, Milbrandt JD, Krause JE: Differential expression of insulin-like growth factor genes in rat central nervous system. Proc Natl Acad Sci U S A 1988; 85: 265-269. 